survey found that about half the mothers of triplets and three quarters of those expecting quadruplets were initially admitted for rest alone. Women varied in their views about such a policy, some feeling reassured, others feeling anxious and stressed - particularly about the effects on their families. The report highlighted the costs to the NHS and their families of admission, an intervention without evidence of benefit.

Most reviews of managing triplet pregnancy concentrate on relating outcome to the mode of delivery. ${ }^{3-5}$ No consensus, however, has been reached about the optimum method as controlling for confounding variables, particularly gestational age, is difficult. In several studies only those women whose labours began very early were allowed to deliver vaginally. Although not helping to resolve this controversy, the survey by the Office of Population Censuses and Surveys highlighted the need for systematic evaluation of caesarean section. It also suggested open discussion with parents about the mode of delivery, likely neonatal problems, and possible outcomes.

Multiple births are likely to be more complicated and to occur at even earlier gestational ages than twins. Birth weights in this survey were similar to those described 40 years agothat is, the more fetuses present the more likely they were to weigh less than $1500 \mathrm{~g}$ at birth. ${ }^{6}$ These very low birthweight infants require long periods of neonatal intensive care, which puts parents under severe strain. The report considers that liaison between hospitals, primary care, and social services could be improved. Better support - both advice and practical aid - could be provided, and this needs coordinating by someone other than the parents, which usually occurs at present.

About $5 \%$ of triplets in this review had a congenital malformation. (Although high, this figure is not directly comparable with national data.) Also of concern is the increased prevalence of cerebral palsy and general ill health and disability in childhood. Because of the design of the follow up questionnaire and responses the authors believe that they have underestimated the size of developmental problems. They call for further long term follow up studies to assess physical and mental handicap and educational problems.

Finally, the cost to the NHS is calculated: each set of twins costs $£ 5000$, each set of triplets $£ 12000$, and each set of quadruplets $£ 25000$. Some $60 \%$ of the estimated cost is for neonatal care, and $20 \%$ is for antenatal care in hospital. The cost to parents of having three or more children at once is greater than having them in succession.

Selective reduction in the first trimester has been suggested as an alternative management in higher order multiple births but raises difficult legal and ethical issues. ${ }^{8}$ Preventing high order multiple pregnancies is clearly the best option given the high costs to mothers, babies, and services. The onus is therefore on those treating infertility to keep multiple births to a minimum.

Senior Lecturer in Obstetrics and Gynaecology,

DORIS M CAMPBELL

University of Aberdeen,

Aberdeen AB9 2ZD

1 Botting BJ, MacFarlane AJ, Price FV, eds. Three, four, and more. A study of triplet and higher order births. London: HMSO, 1990.

2 Hall MH. Rest in hospital and twin pregnancy. Br f Obstet Gynaecol 1990;97:869-71.

3 Campbell DM, MacGillivray I. Management of labour and delivery: higher multiples. In MacGillivray I, Campbell DM, Thompson B, eds. Twinning and twins. Chichester: John Wiley and Sons, 1988:158-60

4 Crowther CA, Hamilton RA. Triplet pregnancy: a 10 year review of 105 cases at Hapore Maternity Hospital, Nigeria. Acta Genet Med Gemellol (Roma) 1989;38:271-8.

5 Lipitz S, Reichman B, Paret C, et al. The improving outcome of triplet pregnancies. Am f Obstet Gynecol 1989;161:1279-84.

6 McKeown T, Record RG. Observations of fetal growth in multiple pregnancy in man. $\mathcal{F}$ Endocrinol 1952;8:386-401.

7 Berkowitz RL, Lynd L, Chitkara U, et al. Selective reduction of multifetal pregnancies in the first trimester. N Engl f Med 1988;318:1043-7.

8 Howie PW. Selective reduction in multiple pregnancy. Legal confusion and ethical dilemmas. BMF $1988 ; 297: 433-4$
Much research into health and disease depends on data collected from many subjects over long periods of time. Primary care is the obvious place to collect these data: general practitioners deal with most episodes of illness and have records of those episodes dealt with elsewhere. Until recently, however, the structure of general practice and the detail of recorded information have militated against such research, ${ }^{1-3}$ except in trained and motivated "spotter" practices. ${ }^{+}$The arrival of computers into general practice brought hopes of improvement. ${ }^{5-7}$

In 1987 the two main suppliers of computers to general practice, VAMP Health and AAH Meditel, offered computers to practices at low cost in return for access to aggregated patient data. (These could be sold to interested parties, pharmaceutical companies being the most obvious customers. ${ }^{8}$ ) Databases covering 1500 general practices and 3 million patients were envisaged, which could be used to examine prescribing habits. Other possibilities existed-for example, monitoring workload, preventive care, ${ }^{9}$ management, and post-prescription events-but recording details of these lay outside the normal contractual obligations.

The early hopes for large databases have not been fulfilled. VAMP's financial difficulties, ending its agreement to purchase aggregated data from practices, brings the viability of these schemes into question. ${ }^{10}$ The main problem, however, has been incomplete recording. On p 766 Jick and colleagues record that in August 1988, when the VAMP scheme had enrolled 1000 doctors, only 75 practices had reached an acceptable standard of recording. Currently only one in three practices is up to standard. ${ }^{11}$ In one winter month in 1989, 89 of 548 Meditel practices recorded no respiratory infections, and a further 26 could not supply data on list size. In those meeting these minimum criteria, influenza was recorded at a rate one quarter of that obtained from the weekly returns to the Birmingham research unit of the Royal College of General Practitioners (p 763). ${ }^{12}$

The poor quality of data is explained by practices consistently recording only what their contracts with the computer suppliers specify. All that are consistently retrievable are patients' ages and addresses, diagnoses resulting in a prescription (only about $70 \%$ of all diagnose ${ }^{13}$ ), and the prescriptions themselves. All other data recorded by practices depend on individual preference, which varies within and among practices. The absence of medical, social, and occupational histories obviously limits the value of the databases for epidemiological research and hypothesis testing.

Perhaps their best use at present (as suggested by the two 
papers in this issue) is for recording changes in prescribing and diagnoses, although too much reliance should not be placed on using these data for drug surveillance. Jick and colleagues decided not to collect prescribing information from the many practices with inadequate records: their evidence of adverse reactions to non-steroidal anti-inflammatory drugs therefore came from a highly selected group of doctors, who may have been more observant and careful prescribers. To identify problems early, schemes monitoring the safety of drugs should include a representative sample of doctors.

We believe that the potential for computerised databases in general practice is too important to leave to the vagaries of the market place. Motivated practices can record data to a high standard, ${ }^{1+15}$ but this is more likely to occur when practices have training and support and every consulting desk has a computer terminal. Smaller list sizes and longer consultation times would also help.

More government investment in practice databases seems logical given the needs of the Department of Health and health authorities for epidemiological information. Inadequately reimbursing the costs of computers and limiting expenditure on practice staff - the legacy of the 1990 general practitioner contract-is likely to limit realising the full potential of general practice databases.

Agreement should be reached over what is recorded and how. Adopting the Read classification for primary care data is encouraging, ${ }^{16}$ but confusion still exists over details such as codes identifying doctors and minimum data sets. Large databases in primary care could one day become powerful tools for research. Much of the hardware is already in place: the next step is convincing general practitioners of the value of keeping high quality records and persuading the NHS of the value of supporting such activity.

MIKE PRINGLE Senior Lecturer

Department of General Practice,

Nottingham University Medical School,

Nottingham NH7 2UH

Department of General Practice,

RICHARD HOBBS Senior Lecturer

University of Birmingham,

Birmingham B50 2TJ

1 Mant D, Tulloch A. Completeness of chronic disease registration in general practice. $B M J$ 1987;294:223-4

Mant $\mathrm{D}$, Phillips $\mathrm{A}$. Can the prevalence of disease risk factors be assessed from general practice records? $B M \mathcal{F}$ 1986;292:102-4.

3 Mansfield BG. How bad are medical records? A review of the notes received by a practice. $f \mathrm{R} C o l l$ Gen Pract 1986;36:405-6.

Campbell DM, Paixao MT, Reid D. Influenza and the "spotter" general practitioner. $f$ R Coll Gen Pract 1988;38:418-21.

Difford F. Performance review using sequential sampling and a practice computer. Family Practice 1988;5:136-41.

6 Weingarten MA, Bazel D, Shannon HS. Computerized protocol for preventive medicine: controlled self audit in family practice. Family Medicine 1989;6:120-4.

controlled self audit in family practice. Family Medicine 1989;6:120-4. 8 Pringle M. Greeks bearing gifts. BMF 1987;295:738-9.

9 Pringle M. Greeks bearing gifts. BMF 1987;295:738-9. Lawrence M, Coulter A, Jones L. A total a
430000 patients. BMf 1990;300:1501-3.

10 Beecham L. Re: VAMP revamp. BMF 1991;302:489-90.

11 Jick $\mathrm{H}$, Jick SS. Derby LE. Validation of information recorded on general practitioner based computerised data resource in United Kingdom. BMf 1991;302:766-8.

12 Johnson N, Mant D, Jones L, Randall T. Use of computerised general practice data for population surveillance: comparative study of influenza data. BMJ 1991;302:763-5.

13 Lee PR. Medication and prescribing. In: Fry J, ed. Primary care. London: Heinemann Medical, 1980:230-51.

14 Royal College of General Practitioners, Office of Population Censuses and Surveys, Department of Health and Social Security. Morbidity statistics from general practice: third national study. London HMSO, 1986.

15 Fleming DM, Lawrence MS. Impact of audit on preventive measures. BMf 1983;287:1852-4.

16 Read JD, Benson TJR. Comprehensive coding. British fournal of Healthcare Computing 1986;3: $22-5$.

\section{What is a normal upper gastrointestinal tract?}

\section{One that has been underinvestigated?}

What are we to make of the study by Johnsen and colleagues (p 749), which found that only one in 10 people had an entirely normal upper gastrointestinal tract? ${ }^{1}$ This conclusion was reached after endoscopic and histological examinations of 309 people with dyspepsia and 310 without. Perhaps the humorist who remarked that "a normal person is someone who has been insufficiently investigated" was right.

Not all the abnormalities that were found caused symptoms. Although "visual" duodenitis was more common in patients with dyspepsia, "histological" duodenitis was slightly more common in those without. While active chronic gastritis was found more often in the dyspeptic group, well over half of the control subjects had evidence of gastritis on histological examination. No correlation was found between specific symptoms and endoscopic or histological findings.

This emphasises the need for endoscopists not only to document accurately the visual appearances but also, where appropriate, to biopsy - which may confirm or contradict their original opinion. They must also take special care when interpreting the findings for others. Non-specialists may not know that a condition such as diffuse atrophic gastritis is unlikely to cause symptoms. Its appearance on a report may lead to wrongly attributing clinically important symptoms to clinically irrelevant mucosal changes.
Endoscopy has taught us much about gastrointestinal disease, but its limitations should not be forgotten. While overt mucosal lesions are readily and accurately detected endoscopy is not as good at assessing function. Furthermore, the causes of symptoms may not be detectable. (The presence of clinically relevant gastrooesophageal reflux despite normal endoscopic appearances is a case in point. ${ }^{2}$ )

So what is a normal upper gastrointestinal tract? Normal is not the same as common: more than half the middle aged population is infected with Helicobacter pylori, but that does not make it normal. For the individual, a normal upper gut is one that does what is asked of it without complaint. For doctors and scientists, much more research stands between them and a working definition of normality.

Consultant Physicians and

D G COLIN-JONES P L GOLDING

Gastroenterologists,

Queen Alexandra Hospital,

Cosham,

Portsmouth PO6 3LY

1 Johnsen R, Bernersen B, Straumè B, Forde OH, Bostad L, Burhol PG. Prevalences of endoscopic and histological findings in subjects with and without dyspepsia. BMF 1991;302: $749-51$.

2 Johnsson F, Joelsson B. Reproducibility of ambulatory oesophageal pH monitoring. Gut 1988;29. $886-9$. 